\title{
Appraisal and Current Considerations of Robotics in Colon and Rectal Surgery
}

\author{
Ciro Andolfi, MD, and Konstantin Umanskiy, MD
}

\begin{abstract}
Background: Robotic technology aims to obviate some of the limitations of conventional laparoscopic surgery, yet the role of robotics in colorectal surgery is still largely undefined and varies with respect to its application in abdominal versus pelvic surgery.

Methods: With this review, we aimed to highlight current developments in colorectal robotic surgery. We systematically searched the following databases: PubMed, EMBASE, and Cochrane Library. We critically reviewed the available literature on the use of robotic technology in colon and rectal surgery.

Results: Robotic colorectal surgery is oncologically safe and has short-term outcomes comparable to conventional laparoscopy, with potential benefits in rectal surgery. It has a shorter learning curve but increased operative times and costs. It offers potential advantages in the resection of rectal cancer, due to lower conversion rates. There is also a trend toward better outcomes in anastomotic leak rates, circumferential margin positivity, and perseveration of autonomic function.

Conclusion: Laparoscopy remains technically challenging and conversion rates are still high. Therefore, most cases of colorectal surgery are still performed open. Robotic surgery aims to overcome the limits of the laparoscopic technique. This new technology has many advantages in terms of articulating instruments, advanced three-dimensional optics, surgeon ergonomics, and improved accessibility to narrow spaces, such as the pelvis. However, further studies are needed to assess long-term results and benefits.
\end{abstract}

Keywords: robotic surgery, robotic colectomy, robotic rectopexy, robotic transanal total mesorectal excision, TME

\section{Introduction}

$\mathbf{T}$ HE USE OF MINIMALLY INVASIVE SURGERY in colon and rectal practice has increased dramatically over the past four decades and more recently robotic-assisted surgery has led the advances in this field. Robotics in colorectal surgery has been gaining popularity since the da Vinci surgical system (Intuitive Surgical) was introduced to the market in 2001. The main purpose of the robot was to overcome the limitations of laparoscopic surgery such as difficulty of operating in the confines of a narrow bony pelvis, particularly in obese men with radiated low rectal cancer. Additional advantages of robotic technology include popularization of intracorporeal bowel anastomosis that has been notoriously technically difficult to perform laparoscopically. With this article, we aim to assess the evidence on the feasibility, safety, and efficacy of robotics in colorectal surgery.

\section{Robotic Colectomy}

The first report on laparoscopic right colectomy was published by Jacobs et al. ${ }^{1}$; shortly following that Fowler performed the first laparoscopic left colectomy. Since these initial reports, several large studies found that the oncologic outcomes of laparoscopic colectomy were equivalent to open surgery. Despite the growing evidence supporting the use of laparoscopic colectomy for colon cancer, the adoption of this technique was relatively slow due to some limitations: loss of stereoscopic vision and depth perception, paradoxical motion of the instruments, amplified movements, parallel instrumentation, and suboptimal ergonomics. To overcome these shortfalls, the use of hand-assisted laparoscopy was introduced as a bridge between open and laparoscopic surgery. ${ }^{2,3}$ Robotic colectomy was first reported in 2002 and since that time adoption of robotic surgery has steadily increased, as evidenced by the number of publications in both medical and lay press.

The da Vinci robotic system, the only currently available robotic system in the market approved by the FDA for colorectal surgery, provides several advantages over traditional laparoscopic surgery including a stable camera platform, threedimensional (3D) imaging, improved ergonomics, tremor elimination, ambidextrous capability, motion scaling, and

Department of Surgery, Section of Colon and Rectal Surgery, and Center for Simulation, The University of Chicago Pritzker School of Medicine, Chicago, Illinois. 
instruments with multiple degrees of freedom. Studies comparing the outcomes of laparoscopic versus robotic colectomy and overall, robotic-assisted right colectomy had similar perioperative and oncologic outcomes at the expense of longer operation times and increased surgical costs. Some studies suggest there may be an advantage to robotic right colectomy with regards to decreased estimated blood loss (EBL), shorter length of stay, and faster return of bowel function. ${ }^{4-6}$

Although no significant clinical benefit from robotic surgery has been demonstrated, some authors argue that robotic right colectomy could be considered as initial procedure the surgeons adopt early in their learning curve before undertaking more complex operations such as a low anterior resection. ${ }^{7}$ This is the reason why many surgeons view right colectomy as a "gateway" to robotic surgery with the intent to progress to more complex operations once they ascend the learning curve. deSouza et al. ${ }^{7}$ retrospectively analyzed 40 cases of robotic right colectomy and compared them with 135 procedures performed with conventional laparoscopy. This report failed to demonstrate a benefit of robotic surgery compared to conventional laparoscopy in terms of conversion rate, postoperative outcome, and oncologic outcomes. In addition, the authors performed a careful cost analysis that showed that robotic operations took significantly longer to perform and were associated with increase in costs compared with laparoscopic right colectomy. The authors concluded that robotic right colectomy is safe and feasible and, despite the added cost, may serve as a useful initial operation at the beginning of the robotic learning curve. ${ }^{7}$

Similarly, Akmal et al. ${ }^{8}$ hypothesized that practicing robotic surgery with other surgical procedures, including right colectomy, can decrease the learning curve for minimally invasive rectal surgery. Their study included 80 patients who underwent total mesorectal excision (TME) performed by a single surgeon with experience in minimally invasive surgery, who previously performed 20 laparoscopic TMEs but no robotic TMEs. The operative experience was divided into two groups: first 40 cases (group 1) and subsequent 40 cases (group 2). There were no differences in mean operative time, EBL, margin status, lymph nodes (LN) harvested, conversion rate, resumption to diet, length of hospital stay or postoperative complications between the two groups. These findings supported the idea that robotic "gateway" procedures can be used to bypass the steep learning curve for minimally invasive rectal surgery. ${ }^{8}$ In addition, in a recent study by Widmar et al. ${ }^{9}$ the authors retrospectively reviewed 181 open, 163 laparoscopic, and 119 robotic right colectomies performed at the Memorial Sloan Kettering Cancer Center in New York. They found that robotic right colectomy improves $\mathrm{LN}$ yield and the $\mathrm{LN}$ to length of surgical specimen ratio, which may reflect a better and more precise mesocolic excision. ${ }^{9}$

Left colectomy is a more challenging procedure when compared with right colectomy. Other than being more technically demanding, left colectomy requires a colo-colonic or colorectal anastomosis and has a significantly higher incidence of anastomotic leak, wound infection, overall complication rate (ureteral injury, conversion, etc.), and longer length of hospital stay than right colectomy.

There have been several published techniques for robotic left colectomy: hybrid (laparoscopic splenic flexure mobilization), single docking (mobilizing the second and third robotic arms for different parts of the surgery), double docking (docking once for splenic flexure mobilization, then redocking for the rest of the procedure), and most recently a "singleposition flip arm technique" that allows for splenic flexure mobilization and low anterior resection with only one docking position. With the latter technique the robot is placed to the left side of the patient. The camera port is placed $3 \mathrm{~cm}$ to the right of the umbilicus; the first arm is placed in the right lower quadrant; the second arm is placed in the mid-epigastric area, at least $8 \mathrm{~cm}$ away from the camera; the third arm is placed in the left lower quadrant. The last arm is the one that will "flip" toward the pelvis during the case. An assistant port can be placed in the right flank, slightly cephalad and lateral to the right lower quadrant robotic port. ${ }^{10}$

Several studies have compared outcomes robotic versus laparoscopic left colectomy. As in robotic right colectomy, robotic left colectomy had similar perioperative and oncologic outcomes with increased operative times. Casillas et al., ${ }^{11}$ in a prospective study including 344 patients undergoing robotic or laparoscopic colorectal procedures, found that there was no difference between laparoscopic and robotic left colectomies with respect to the EBL, conversion rate, and average number of $\mathrm{LN}$ harvested. In addition, the authors found that the average length of hospital stay was almost 3 days longer for laparoscopic versus robotic left colectomies. Conversely, the operative time was significantly shorter for laparoscopic left colectomies. ${ }^{11}$ Similarly, Davis et al. ${ }^{12}$ analyzed data of patients undergoing laparoscopic and robotic left colectomy, extracted by the Premier Hospital Database. The authors found that laparoscopic and robotic left colectomies are similar with respect to clinical outcomes and perioperative complications. However, robotic procedures were associated with higher hospital costs and longer surgical times.

Two other relevant clinical studies have directly compared robotic and laparoscopic left colectomies. In a retrospective study of 105 patients undergoing laparoscopic or robotic left colectomy, Deutsch et al. ${ }^{4}$ showed an increase in operative time for the robotic group and a similar length of stay between the robotic and the laparoscopic groups. Similarly, Rawlings et al. ${ }^{13}$ studied 25 patients undergoing left colectomy, and found an increase in mean operative time for the robotic group and similar mean length of stay between the two groups.

Data reported in current literature show that robotic assistance may confer some advantages regarding perioperative complications and length of hospital stay after right and left colectomies. In addition, robotic right colectomy can be considered a "gateway" procedure to perform more challenging surgeries.

\section{Robotic Anastomosis after Right Colectomy}

Extracorporeal anastomosis, which requires additional mobilization of the colon to exteriorize the bowel through a mini-laparotomy incision, is the most common method used to create an ileocolic anastomosis after laparoscopic right colectomy. This is largely because the use of straight, nonarticulating laparoscopic instruments makes a laparoscopic intracorporeal anastomosis difficult and time consuming. Some studies have shown benefits of intracorporeal anastomosis over extracorporeal anastomosis in right colectomy, such as faster return of bowel function, shorter length of stay, and reduced use of pain medications. ${ }^{14}$ Robotic surgery, with its advantages of wristed instruments and a 3D image, in addition to the release of the Robotic EndoWrist Stapler, may 
help overcome the difficulty of performing intracorporeal anastomosis.

Two small single center retrospective reviews published in 2013 and 2015 reported their outcomes of 20 and 52 patients, respectively, who underwent a robotic right colectomy with intracorporeal anastomosis. They found only one anastomotic leak and no conversions, intraoperative complications, or 30day mortalities. The authors concluded that robotic right colectomy with intracorporeal anastomosis is a safe and feasible approach. ${ }^{15,16}$ Another retrospective review in which the authors studied 89 patients undergoing robotic colectomy and 135 undergoing laparoscopic colectomy, found that robotic right colectomy with intracorporeal anastomosis was associated with shorter incision length, decreased rates of incisional hernia and anastomotic leak, and less EBL when compared with laparoscopic right colectomies with extracorporeal anastomosis. ${ }^{17}$

A large retrospective multicenter study of 236 patients found no significant difference in conversion rates, morbidity or mortality rates, or average number of $\mathrm{LN}$ harvested when robotic right colectomy with intracorporeal anastomosis was compared with laparoscopic right colectomy with intracorporeal anastomosis and extracorporeal anastomosis. ${ }^{18}$ In addition, robotic right colectomy with intracorporeal anastomosis showed significantly decreased time to flatus and shorter length of stay compared with laparoscopic right colectomies with extracorporeal anastomosis. At this time, even if no published prospective randomized trials have been performed, the current literature suggests that robotic right colectomy with intracorporeal anastomosis is safe and feasible.

\section{Robotic TME}

TME is the complete removal of the lymphatics and $\mathrm{LN}$ of the perirectal envelope-mesorectum and is currently considered the "gold standard" technique in the surgical treatment of rectal cancer. Both the quality of TME and the involvement of the circumferential resection margin (CRM) correlate with rates of recurrence and long-term survival. ${ }^{19,20}$ The comparison of open versus laparoscopic surgery for mid or low rectal cancer after neoadjuvant chemoradiotherapy noninferiority (COREAN) trial randomized 340 patients at three centers in South Korea to open or laparoscopic TME. $^{21,22}$ It found no significant differences between CRM positivity rates or quality of TMEs. Therefore, it was concluded that laparoscopic surgery, when performed by qualified surgeons, can result in noninferior survival outcomes compared with open surgery. In addition, two large multicenter noninferiority randomized controlled trials (RCTs) published in 2015, the Australasian Laparoscopic Cancer of the Rectum (ALaCaRT) trial $^{23}$ and the American College of Surgeons Oncology Group (ACOSOG) Z6051 trial, ${ }^{24}$ assessed whether the laparoscopic approach for rectal cancer is noninferior to open resection. Successful resection was assessed by laparoscopy but neither trial could establish noninferiority of laparoscopic to open resection and the authors concluded that the evidence did not support the use of laparoscopy for rectal cancer.

With its wristed instruments for improved dexterity in narrow spaces such as pelvis, robotic surgery for rectal cancer has been promoted as a superior minimally invasive alternative to standard laparoscopy. The current literature comparing robotic, laparoscopic, and open resections for rectal cancer in- cludes systematic reviews, meta-analyses, large retrospective series, and single center reviews. A large U.S. national database review looked at 16,275 patients from the National Cancer Database who underwent robotic, laparoscopic, or open low anterior resection. ${ }^{25}$ The authors found no significant differences between open versus laparoscopic surgery, or open versus robotic surgery in rates of positive margins, number of retrieved $\mathrm{LN}$, readmission rates, or 30-day mortality. Laparoscopic and robotic surgery was associated with decreased length of stay compared with open surgery, but robotic surgery was associated with lower rates of conversion to open surgery when compared with laparoscopic surgery.

A 2015 systematic review and meta-analysis included 2224 patients from 17 studies that compared robotic versus laparoscopic approaches for rectal cancer. ${ }^{26}$ It was found that, compared with the laparoscopic approach, robotic surgery was associated with significantly lower rates of conversion and decreased time to flatus. A systematic review and metaanalysis of seven studies with 1074 patients compared the safety and efficacy of robot-assisted versus open surgery in rectal cancer. ${ }^{27}$ Robotic-assisted surgery was associated with decreased intraoperative blood loss (EBL), shorter length of stay, and shorter time to flatus, but longer operation times. There were no differences in complications, distal resection margin, or disease-free survival between the two groups. Another meta-analysis assessed 24 studies, including two RCTs, with 3318 patients, compared robotic versus laparoscopic surgery for colorectal cancer. ${ }^{28}$ The robotic group had significantly lower rates of conversion. There was no difference in postoperative complication rates, distal resection margins, or costs. Although EBL and length of stay were lower in the robotic group, there was significant heterogeneity between the groups. Recovery of sexual and urologic function was also better in patients who had undergone robotic surgery compared with laparoscopy for rectal cancer.

A retrospective review with 40 patients in each group showed greater improvement of sexual function using the International Index of Erectile Function (IIEF) score at 3 and 6 months after robotic resection compared with laparoscopic resection. ${ }^{26}$ As for the oncologic outcomes, a few studies have also assessed whether robotic surgery provides good oncologic outcomes with regard to the quality of TME, rates of CRM positivity, and disease-free survival. A retrospective matched cohort study compared robotic versus open and laparoscopic techniques for rectal cancer with 165 patients in each group. ${ }^{29}$ Time to flatus, resumption of diet, and length of stay were significantly lower in the robotic and laparoscopic groups compared with the open group. Rates of CRM involvement were also reduced in the robotic group compared with the open group and no differences were seen in diseasefree survival at 2 years between the groups.

Another matched cohort study that compared patients undergoing robotic-assisted TME with those who had undergone laparoscopic TME in the past found that the robotic group had significantly better CRM than the laparoscopic group but no differences in the number of harvested LN. ${ }^{30}$ Accordingly, a more recent retrospective study published in 2017 compared robotic versus laparoscopic resections and found no significant difference in length of stay, overall morbidity rates, quality of TME, or rates of CRM positivity. ${ }^{31}$

The Robotic versus Laparoscopic Resection for Rectal Cancer (ROLARR) trial has recently been completed. This 
international multicenter prospective RCT randomized 471 patients from 29 centers in 10 countries to robotic versus laparoscopic resections for rectal cancer. ${ }^{32}$ The primary outcome was the conversion rate, and the secondary outcomes included 30-day morbidity and mortality, CRM positivity, 3-year local recurrence rate, disease-free and overall survival rates, and sexual and urinary complications. The study found no significant difference in conversion rate between laparoscopic and robotic approaches. In addition, no significant differences were seen in CRM positivity, TME completion, rates of intraoperative complications, postoperative complications, or 30-day mortality. Subgroup analysis found an improvement in conversion rates in robotic versus laparoscopic surgery in men and the authors speculated that robotic surgery may have greater benefit than laparoscopy in the narrower male pelvis. Even though this large multicenter study had the limitation of including surgeons with a wide range of experience in robotic surgery, it did not show a significant benefit of robotics over laparoscopy in the treatment of rectal cancer.

\section{Robotic Transanal TME}

The transanal TME (taTME) uses an innovative bottom-up approach through the anus, which was developed to improve the quality and outcomes of distal TME in the treatment of rectal cancer. It is a type of natural orifice transluminal endoscopic surgery (NOTES) that mobilizes the rectum using endoscopic and sometimes laparoscopic techniques. Initial small studies comparing taTME with laparoscopic TME have shown that this taTME is feasible and can yield better quality of TME compared to transabdominal TME. This translates in wider CRM, with lower rates of CRM positivity. However, recent studies have shown that complication rates, such as injury to the urethra and anastomotic leak, are higher than those seen with conventional transabdominal TME. A robotic-assisted taTME is therefore being developed. In this approach, robotic trocars are placed through a single incision laparoscopic surgery port, such as the GelPOINT, which is inserted transanally. Several pilot studies have shown the safety and feasibility of this approach. ${ }^{33-38}$

Another application of the robotic technology is for transanal excision of rectal polyps and early rectal cancer. Transanal endoscopic microsurgery first introduced in 1983 by Dr. Gerhard Buess has recently undergone several modifications with popularization of trans-anal minimally invasive surgery (TAMIS) excisions of benign polyps and early rectal tumors. ${ }^{33}$ Similar to the taTME approach, a single laparoscopic access port is placed through the anus into the rectal vault and standard laparoscopic instruments are used to resect benign rectal polyps or early stage rectal cancers. Both TAMIS and transanal endoscopic microsurgery have been shown in retrospective and systematic reviews and metaanalyses to be safe and feasible, although transanal endoscopic microsurgery has the disadvantages of higher costs and a steeper learning curve. ${ }^{39-46}$ Like any single incision laparoscopic procedure, TAMIS still has its challenges, such as colliding instruments, torque forces causing leakage of insufflation, and the lack of articulating instruments.

Robotic TAMIS was described in 2011, when it was carried out on a cadaveric model. ${ }^{34}$ To date, only small case series and case reports have demonstrated the feasibility of robotic TAMIS for the local excision of rectal tumors. Robotic-assisted taTME and TAMIS are both novel methods being studied for the treatment of rectal tumors. Future large RCTs are needed to investigate the short-term and long-term clinical and oncologic outcomes in addition to the costbenefit of these approaches. The advantages of the robotic articulating instruments and improved optics in combination with a NOTES approach may prove to be an emerging technique in the future of robotic surgery.

\section{Robotic Rectopexy}

There are several different types of procedure described for the management of rectal prolapse in adults. These techniques are generally classified in two types: perineal procedures that tend to be considered less invasive but have higher recurrence rates, or transabdominal procedures that are more invasive but tend to have lower recurrence rates. Large RCTs are lacking, but several comparative studies and meta-analysis have demonstrated overall advantage of a minimally invasive approach for transabdominal management of rectal prolapse. Compared with traditional laparotomy, laparoscopic rectopexy was associated with longer operative times but shorter hospital length of stay, lower recurrence rates, and better long-term functional results.

In 2004, D'Hoore et al ${ }^{47}$ reported their initial experience with 42 laparoscopic ventral rectopexies. The authors concluded that this is an effective technique for the correction of rectal prolapse, which also appears to avoid postoperative severe constipation. More recently, Consten et al., ${ }^{48}$ in a multicenter study involving 919 patients undergoing laparoscopic ventral rectopexy, demonstrated that this technique is safe and effective for the treatment of different rectal prolapse syndromes. The authors demonstrated that both fecal incontinence and obstructed defecation decreased significantly after laparoscopic rectopexy compared with the preoperative incidence. In addition, the recurrence rate at 5 years was only $10 \%$.

The first case series of six patients who underwent robotic suture rectopexy for rectal prolapse was reported by Munz et al. ${ }^{49}$ in 2004. Since then several other case series using a variety of techniques have been described. ${ }^{50-52}$ Outcomes in these studies showed low recurrence rates and good functional outcomes. A recent meta-analysis comparing laparoscopic to robotic ventral mesh rectopexy found that robotic rectopexy had similar functional outcomes and conversion rates compared with laparoscopy but longer operative times with increased costs. ${ }^{53}$ However, in terms of recurrence rates after surgery, de Hoog et al. reported significantly higher rates 2 years after robotic rectopexy. ${ }^{54}$ Nonetheless, all articles shared the limitations of small sample size and shortterm follow-up.

\section{Costs of Robotic Colorectal Surgery}

One of the biggest criticisms of robotic surgery is its cost. The da Vinci surgical system is the only currently available surgical robot on the market, and it has a high upfront cost, ranging from $\$ 1$ to $\$ 2.5$ million per unit. The learning curve in robotic surgery must also be considered in the cost analysis. The goal of developing a multivariable learning curve is to calculate the number of procedures performed under supervision or in a simulated environment that a surgeon may have to carry out before reaching a safe and competent level 
of independent performance. ${ }^{55}$ Several studies have shown that as a surgeon's experience increases, operative times and outcomes improve, which leads to reduced overall costs. ${ }^{56} \mathrm{~A}$ retrospective review of a single surgeon's 85 consecutive robotic-assisted rectal dissections from 2010 to 2012 analyzed the difference in operative times and direct hospital costs between the first 43 cases and the last 42 cases. $^{57}$ The mean operative time was significantly lower in the latter group compared with the first. Direct hospital costs were lower in the latter group but this was not significant.

A similar retrospective study compared the costs of a single surgeon's first 50 robotic versus laparoscopic rectal resections. ${ }^{58}$ The study also compared operative times and costs as a function of experience within the robotic group, separating the 50 cases into three phases: the initial learning curve (cases 1-19), competent period (cases 20-40), and experienced phase (cases 41-50). On average, the operative times and overall costs were significantly higher in the robotic group than in the laparoscopic group. However, operative times and costs were significantly reduced in the experienced phase of robotic cases compared with the initial learning curve. In addition, when fixed costs (costs of the nondisposable robotic instruments plus the purchasing and maintenance of the robotic system) were excluded, no statistically significant difference was seen between the laparoscopic group and the experienced phase robotic group.

These studies suggest that when surgeons surpass their learning curves and increase their annual caseload, robotic operative times should improve and overall costs should fall. Lately, Vasudevan et al. ${ }^{59}$ performed retrospective review that compared 227 patients who underwent laparoscopic or robotic colorectal surgery. The authors found no significant difference in terms of overall hospital charges and short-term clinical outcomes, including length of stay and conversion rates. In addition, they found that robotic surgery was favored for left-sided colectomy. The authors concluded that "with shorter learning curves and wider availability, robotic approach offers a safe and economically feasible minimally invasive platform for complex colorectal resections."

The literature on robotic surgery and its costs is still conflicting. As described earlier, the robotic approach to colorectal surgery has been associated with decreased length of stay and decreased readmission and complication rates, which may offset the additional operative time and expense of the robotic equipment. With the improvements in clinical outcomes, the increasing expertise of surgeons in robotics, and efforts to reduce the fixed costs of the robotic surgical system, robotic surgery may prove to be a cost-effective approach.

\section{Future Directions}

The technique of single incision robotic colectomy using a GelPOINT port has been widely described by Juo et al. in the largest retrospective review that included 59 patients. ${ }^{60}$ In their study the authors reported four conversions to laparotomy, three conversions to multiport robotic approach, and one conversion to single port laparoscopy. Conversions were caused by poor visualization, extensive adhesions, and malfunctioning equipment. Although this study, among other smaller case series, ${ }^{61,62}$ has shown that the technique is feasible, further investigation are needed to evaluate its safety. In addition, there are no studies comparing the single incision robotic colectomy with multi-port robotic or laparoscopic approaches, and no studies have assessed the oncologic outcomes with this technique.

For the last 20 years, the predominant robot used in surgery has been da Vinci by Intuitive Surgical. This monopoly has led to rising costs and relatively slow innovation. The rise of Intuitive Surgical has been spectacular with more than 750,000 procedures performed worldwide last year. ${ }^{63}$ However, there is still an issue with the use of the da Vinci system. The cost of the equipment is gigantic and insurers do not always reimburse the extra amount of money for robotic surgery over the costs of other minimally invasive techniques. The lack of competition for the da Vinci has precluded any control on costs, and their supremacy has caused a lack of true innovation. In the last 2 years, we have only seen two new potential rivals: the Senhance and the REVO-I. However, with major players like Medtronics and Verb Surgical (powered by Google and Johnson \& Johnson) launching their devices in the next couple of years we foresee a competition that will potentially drive innovation as well as lower the prices.

\section{Conclusion}

Robotic surgery aims to overcome the limits of the laparoscopic technique. Recent studies have shown robotic colorectal surgery to be oncologically safe and to offer short-term outcomes comparable to conventional laparoscopic techniques, with potential benefits in rectal surgery. In addition, because laparoscopy remains technically challenging and conversion rates are still high, most cases of colorectal surgery are still performed open. Robotic surgery has many advantages over laparoscopy in terms of articulating instruments, advanced 3D optics, surgeon ergonomics, and improved accessibility to narrow spaces such as the pelvis and reduction in conversion rates. However, further studies are required to assess the long-term results and potential benefits of robotic surgery over laparoscopy.

\section{Disclosure Statement}

No competing financial interests exist.

\section{References}

1. Jacobs M, Verdeja JC, Goldstein HS. Minimally invasive colon resection (laparoscopic colectomy). Surg Laparosc Endosc 1991;1:144-150.

2. Memon MA, Fitzgibbons RJ, Jr. Hand-assisted laparoscopic surgery (HALS): A useful technique for complex laparoscopic abdominal procedures. J Laparoendosc Adv Surg Tech A 1998;8:143-150.

3. O'Reilly MJ, Saye WB, Mullins SG, Pinto SE, Falkner PT. Technique of hand-assisted laparoscopic surgery. J Laparoendosc Surg 1996;6:239-244.

4. Deutsch GB, Sathyanarayana SA, Gunabushanam V, Mishra N, Rubach E, Zemon H, et al. Robotic vs. laparoscopic colorectal surgery: An institutional experience. Surg Endosc 2012;26:956-963.

5. Morpurgo E, Contardo T, Molaro R, Zerbinati A, Orsini C, D'Annibale A. Robotic-assisted intracorporeal anastomosis versus extracorporeal anastomosis in laparoscopic right hemicolectomy for cancer: A case control study. J Laparoendosc Adv Surg Tech A 2013;23:414-417. 
6. Rondelli F, Balzarotti R, Villa F, Guerra A, Avenia N, Mariani E, et al. Is robot-assisted laparoscopic right colectomy more effective than the conventional laparoscopic procedure? A meta-analysis of short-term outcomes. Int $\mathbf{J}$ Surg 2015;18:75-82.

7. deSouza AL, Prasad LM, Park JJ, Marecik SJ, Blumetti J, Abcarian H. Robotic assistance in right hemicolectomy: Is there a role? Dis Colon Rectum 2010;53:1000-1006.

8. Akmal Y, Baek JH, McKenzie S, Garcia-Aguilar J, Pigazzi A. Robot-assisted total mesorectal excision: Is there a learning curve? Surg Endosc 2012;26:2471-2476.

9. Widmar M, Keskin M, Strombom P, Beltran P, Chow OS, Smith JJ, et al. Lymph node yield in right colectomy for cancer: A comparison of open, laparoscopic and robotic approaches. Colorectal Dis 2017;19:888-894.

10. Obias V, Sanchez C, Nam A, Montenegro G, Makhoul R. Totally robotic single-position 'flip' arm technique for splenic flexure mobilizations and low anterior resections. Int J Med Robot 2011;7:123-126.

11. Casillas MA, Jr., Leichtle SW, Wahl WL, Lampman RM, Welch KB, Wellock T, et al. Improved perioperative and short-term outcomes of robotic versus conventional laparoscopic colorectal operations. Am J Surg 2014;208: 33-40.

12. Davis BR, Yoo AC, Moore M, Gunnarsson C. Roboticassisted versus laparoscopic colectomy: Cost and clinical outcomes. JSLS 2014;18:211-224.

13. Rawlings AL, Woodland JH, Vegunta RK, Crawford DL. Robotic versus laparoscopic colectomy. Surg Endosc 2007; 21:1701-1708.

14. Stein SA, Bergamaschi R. Extracorporeal versus intracorporeal ileocolic anastomosis. Tech Coloproctol 2013; 17 Suppl 1:S35-S39.

15. Lujan HJ, Molano A, Burgos A, Rivera B, Plasencia G. Robotic right colectomy with intracorporeal anastomosis: Experience with 52 consecutive cases. J Laparoendosc Adv Surg Tech A 2015;25:117-122.

16. Trastulli S, Desiderio J, Farinacci F, Ricci F, Listorti C, Cirocchi R, et al. Robotic right colectomy for cancer with intracorporeal anastomosis: Short-term outcomes from a single institution. Int J Colorectal Dis 2013;28:807-814.

17. Lujan HJ, Plasencia G, Rivera BX, Molano A, Fagenson A, Jane LA, et al. Advantages of robotic right colectomy with intracorporeal anastomosis. Surg Laparosc Endosc Percutan Tech 2018;28:36-41.

18. Trastulli S, Coratti A, Guarino S, Piagnerelli R, Annecchiarico M, Coratti F, et al. Robotic right colectomy with intracorporeal anastomosis compared with laparoscopic right colectomy with extracorporeal and intracorporeal anastomosis: A retrospective multicentre study. Surg Endosc 2015;29:1512-1521.

19. Parfitt JR, Driman DK. The total mesorectal excision specimen for rectal cancer: A review of its pathological assessment. J Clin Pathol 2007;60:849-855.

20. Quirke P, Steele R, Monson J, Grieve R, Khanna S, Couture $\mathrm{J}$, et al. Effect of the plane of surgery achieved on local recurrence in patients with operable rectal cancer: A prospective study using data from the MRC CR07 and NCICCTG CO16 randomised clinical trial. Lancet 2009;373: 821-828.

21. Jeong SY, Park JW, Nam BH, Kim S, Kang SB, Lim SB, et al. Open versus laparoscopic surgery for mid-rectal or low-rectal cancer after neoadjuvant chemoradiotherapy (COREAN trial): Survival outcomes of an open-label, non- inferiority, randomised controlled trial. Lancet Oncol 2014; 15:767-774.

22. Kang SB, Park JW, Jeong SY, Nam BH, Choi HS, Kim $\mathrm{DW}$, et al. Open versus laparoscopic surgery for mid or low rectal cancer after neoadjuvant chemoradiotherapy (COREAN trial): Short-term outcomes of an open-label randomised controlled trial. Lancet Oncol 2010;11:637-645.

23. Stevenson AR, Solomon MJ, Lumley JW, Hewett P, Clouston AD, Gebski VJ, et al. Effect of laparoscopicassisted resection vs open resection on pathological outcomes in rectal cancer: The ALaCaRT Randomized Clinical Trial. JAMA 2015;314:1356-1363.

24. Fleshman J, Branda M, Sargent DJ, Boller AM, George V, Abbas M, et al. Effect of laparoscopic-assisted resection vs open resection of stage ii or iii rectal cancer on pathologic outcomes: The ACOSOG Z6051 Randomized Clinical Trial. JAMA 2015;314:1346-1355.

25. Speicher PJ, Englum BR, Ganapathi AM, Nussbaum DP, Mantyh CR, Migaly J. Robotic low anterior resection for rectal cancer: A national perspective on short-term oncologic outcomes. Ann Surg 2015;262:1040-1045.

26. Park SY, Choi GS, Park JS, Kim HJ, Ryuk JP. Short-term clinical outcome of robot-assisted intersphincteric resection for low rectal cancer: A retrospective comparison with conventional laparoscopy. Surg Endosc 2013;27:48-55.

27. Liao G, Li YB, Zhao Z, Li X, Deng H, Li G. Roboticassisted surgery versus open surgery in the treatment of rectal cancer: The current evidence. Sci Rep 2016;6:26981.

28. Zhang X, Wei Z, Bie M, Peng X, Chen C. Robot-assisted versus laparoscopic-assisted surgery for colorectal cancer: A meta-analysis. Surg Endosc 2016;30:5601-5614.

29. Kang J, Yoon KJ, Min BS, Hur H, Baik SH, Kim NK, et al. The impact of robotic surgery for mid and low rectal cancer: A case-matched analysis of a 3-arm comparison-open, laparoscopic, and robotic surgery. Ann Surg 2013;257:95101.

30. D'Annibale A, Pernazza G, Monsellato I, Pende V, Lucandri G, Mazzocchi P, et al. Total mesorectal excision: A comparison of oncological and functional outcomes between robotic and laparoscopic surgery for rectal cancer. Surg Endosc 2013;27:1887-1895.

31. Valverde A, Goasguen N, Oberlin O, Svrcek M, Flejou JF, Sezeur A, et al. Robotic versus laparoscopic rectal resection for sphincter-saving surgery: Pathological and short-term outcomes in a single-center analysis of 130 consecutive patients. Surg Endosc 2017;31:4085-4091.

32. Jayne D, Pigazzi A, Marshall H, Croft J, Corrigan N, Copeland $\mathrm{J}$, et al. Effect of robotic-assisted vs conventional laparoscopic surgery on risk of conversion to open laparotomy among patients undergoing resection for rectal cancer: The ROLARR randomized clinical trial. JAMA 2017;318:1569-1580.

33. Atallah S, Nassif G, Polavarapu H, deBeche-Adams T, Ouyang J, Albert M, et al. Robotic-assisted transanal surgery for total mesorectal excision (RATS-TME): A description of a novel surgical approach with video demonstration. Tech Coloproctol 2013;17:441-447.

34. Atallah SB, Albert MR, deBeche-Adams TH, Larach SW. Robotic transanal minimally invasive surgery in a cadaveric model. Tech Coloproctol 2011;15:461-464.

35. Buchs NC, Pugin F, Volonte F, Hagen ME, Morel P, Ris F. Robotic transanal endoscopic microsurgery: Technical details for the lateral approach. Dis Colon Rectum 2013;56: 1194-1198. 
36. Gomez Ruiz M, Parra IM, Palazuelos CM, Martin JA, Fernandez CC, Diego JC, et al. Robotic-assisted laparoscopic transanal total mesorectal excision for rectal cancer: A prospective pilot study. Dis Colon Rectum 2015;58:145-153.

37. Kuo LJ, Ngu JC, Tong YS, Chen CC. Combined robotic transanal total mesorectal excision (R-taTME) and singlesite plus one-port (R-SSPO) technique for ultra-low rectal surgery-initial experience with a new operation approach. Int J Colorectal Dis 2017;32:249-254.

38. Verheijen PM, Consten EC, Broeders IA. Robotic transanal total mesorectal excision for rectal cancer: Experience with a first case. Int J Med Robot 2014;10:423-426.

39. Barendse RM, Dijkgraaf MG, Rolf UR, Bijnen AB, Consten EC, Hoff C, et al. Colorectal surgeons' learning curve of transanal endoscopic microsurgery. Surg Endosc 2013; 27:3591-3602.

40. Clancy C, Burke JP, Albert MR, O'Connell PR, Winter DC. Transanal endoscopic microsurgery versus standard transanal excision for the removal of rectal neoplasms: A systematic review and meta-analysis. Dis Colon Rectum 2015;58:254-261.

41. Jeong WK, Park JW, Choi HS, Chang HJ, Jeong SY. Transanal endoscopic microsurgery for rectal tumors: Experience at Korea's National Cancer Center. Surg Endosc 2009;23:2575-2579.

42. Junginger T, Goenner U, Hitzler M, Trinh TT, Heintz A, Wollschlaeger D, et al. Long-term oncologic outcome after transanal endoscopic microsurgery for rectal carcinoma. Dis Colon Rectum 2016;59:8-15.

43. Keller DS, Haas EM. Transanal minimally invasive surgery: State of the art. J Gastrointest Surg 2016;20:463-469.

44. Lee L, Burke JP, deBeche-Adams T, Nassif G, MartinPerez B, Monson JR, et al. Transanal minimally invasive surgery for local excision of benign and malignant rectal neoplasia: Outcomes from 200 consecutive cases with midterm follow up. Ann Surg 2018;267:910-916.

45. Middleton PF, Sutherland LM, Maddern GJ. Transanal endoscopic microsurgery: A systematic review. Dis Colon Rectum 2005;48:270-284.

46. Rimonda R, Arezzo A, Arolfo S, Salvai A, Morino M. transanal minimally invasive surgery (TAMIS) with SILS port versus transanal endoscopic microsurgery (TEM): A comparative experimental study. Surg Endosc 2013;27: 3762-3768.

47. D'Hoore A, Cadoni R, Penninckx F. Long-term outcome of laparoscopic ventral rectopexy for total rectal prolapse. Br J Surg 2004;91:1500-1505.

48. Consten EC, van Iersel JJ, Verheijen PM, Broeders IA, Wolthuis AM, D'Hoore A. Long-term outcome after laparoscopic ventral mesh rectopexy: An observational study of 919 consecutive patients. Ann Surg 2015;262:742-747; discussion 7-8.

49. Munz Y, Moorthy K, Kudchadkar R, Hernandez JD, Martin S, Darzi A, et al. Robotic assisted rectopexy. Am J Surg 2004;187:88-92.

50. Ayav A, Bresler L, Hubert J, Brunaud L, Boissel P. Robotic-assisted pelvic organ prolapse surgery. Surg Endosc 2005;19:1200-1203.

51. Haahr C, Jakobsen HL, Gogenur I. Robot-assisted rectopexy is a safe and feasible option for treatment of rectal prolapse. Dan Med J 2014;61:A4842.
52. Perrenot C, Germain A, Scherrer ML, Ayav A, Brunaud L, Bresler L. Long-term outcomes of robot-assisted laparoscopic rectopexy for rectal prolapse. Dis Colon Rectum 2013;56:909-914.

53. Ramage L, Georgiou P, Tekkis P, Tan E. Is robotic ventral mesh rectopexy better than laparoscopy in the treatment of rectal prolapse and obstructed defecation? A meta-analysis. Tech Coloproctol 2015;19:381-389.

54. de Hoog DE, Heemskerk J, Nieman FH, van Gemert WG, Baeten CG, Bouvy ND. Recurrence and functional results after open versus conventional laparoscopic versus robotassisted laparoscopic rectopexy for rectal prolapse: A case-control study. Int J Colorectal Dis 2009;24:12011206.

55. Andolfi C, Umanskiy K. Mastering robotic surgery: Where does the learning curve lead us? J Laparoendosc Adv Surg Tech A 2017;27:470-474.

56. Turchetti G, Palla I, Pierotti F, Cuschieri A. Economic evaluation of da Vinci-assisted robotic surgery: A systematic review. Surg Endosc 2012;26:598-606.

57. Byrn JC, Hrabe JE, Charlton ME. An initial experience with 85 consecutive robotic-assisted rectal dissections: Improved operating times and lower costs with experience. Surg Endosc 2014;28:3101-3107.

58. Morelli L, Guadagni S, Lorenzoni V, Di Franco G, Cobuccio L, Palmeri M, et al. Robot-assisted versus laparoscopic rectal resection for cancer in a single surgeon's experience: A cost analysis covering the initial 50 robotic cases with the da Vinci Si. Int J Colorectal Dis 2016;31: 1639-1648.

59. Vasudevan V, Reusche R, Wallace H, Kaza S. Clinical outcomes and cost-benefit analysis comparing laparoscopic and robotic colorectal surgeries. Surg Endosc 2016;30: 5490-5493.

60. Juo YY, Agarwal S, Luka S, Satey S, Obias V. SingleIncision Robotic Colectomy (SIRC) case series: Initial experience at a single center. Surg Endosc 2015;29:19761981.

61. Lim MS, Melich G, Min BS. Robotic single-incision anterior resection for sigmoid colon cancer: Access port creation and operative technique. Surg Endosc 2013;27: 1021.

62. Spinoglio G, Lenti LM, Ravazzoni F, Formisano G, Pagliardi F, Marano A. Evaluation of technical feasibility and safety of single-site robotic right colectomy: Three case reports. Int J Med Robot 2015;11:135-140.

63. Cole AP, Trinh QD, Sood A, Menon M. The rise of robotic surgery in the New Millennium. J Urol 2017;197(2S):S213S215.

Address correspondence to: Konstantin Umanskiy, MD, FACS Department of Surgery Section of Colon and Rectal Surgery and Center for Simulation

The University of Chicago Pritzker School of Medicine 5841 South Maryland Avenue, MC 5095 Chicago, IL 60637

E-mail: kumanskiy@surgery.bsd.uchicago.edu 